\title{
The Dehydrating Oil Plant of Nevada Petroleum Co., California
}

\author{
BY S. J. HARDISON, COALINGA, CAL. \\ (New York Meoting, February, 1915)
}

Is the fall of 1912, the appearance of water in the oil of the Nevada Petroleum Co., Coalinga, Cal., made necessary the installation of a dehydrating plant to reduce the water below the 3 per cent. limit prescribed by the agency.

Unlike the mining industry, technical literature of the oil industry is limited and extremely unsatisfactory. Until the recent efforts of the Petroleum and Gas Committee of the American Institute of Mining Engineers, no concerted movement has been instituted to secure publication of papers dealing with the problems of the oil business, and because of the additional fact that dehydrating of oil has not been practiced in California to any extent up to comparatively recent time, it was found necessary to experiment in order to determine the most satisfactory plan for this purpose.

It is easy to write regarding successful enterprises, but, while not so pleasant, it is equally desirable to write of failures so that others may be saved the loss incident to such investments.

The water in this oil occurs both free and as an emulsion. Free water easily settles out, but the emulsion requires treatment. So far as can be determined, the emulsion consists of globules of water surrounded and enveloped by a film of oil. Starting with this hypothesis the theory has been evolved that in order to break up this emulsion the water must be heated at least to boiling point, when an explosion takes place destroying the globule. Unfortunately, this condition was not recognized in the installation of the first plant, which was planned on the following lines:

A heater was arranged so that all the oil from the wells could be heated before reaching the shipping tanks, these being already fitted with coils for steam heating. Tanks were filled with about $4 \mathrm{ft}$. of water, live steam was turned into the coils and the water brought nearly to the boiling point, when the heated oil was run in. This for a time was partly successful, but the length of time necessary to apply this heat was too great for practical operating. 
The arrangement of the heater plant was as shown in Figs. 1, 2, and 3. Three old boilers were suspended on substantial pipe supports, dry

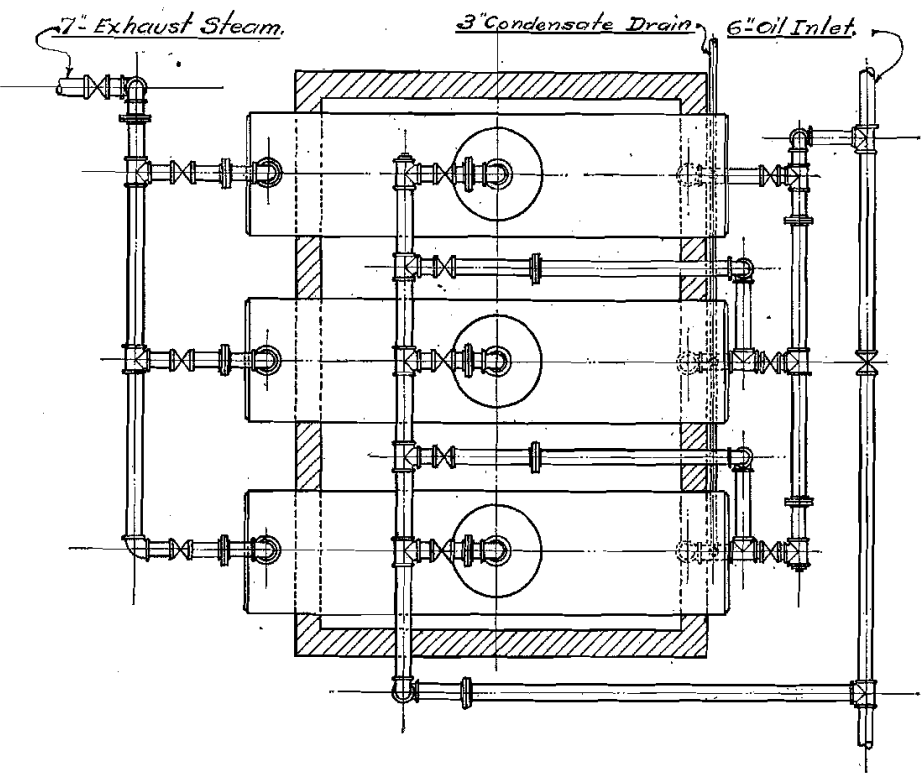

Fig. 1.-Finst Oil-Heating Plant. Plan.

brick walls filled up with oil sands being used to prevent radiation on bottom and side of boilers; the tops of the boilers were covered with bats and oil sand after the pipe work was done. Headers of galvanized

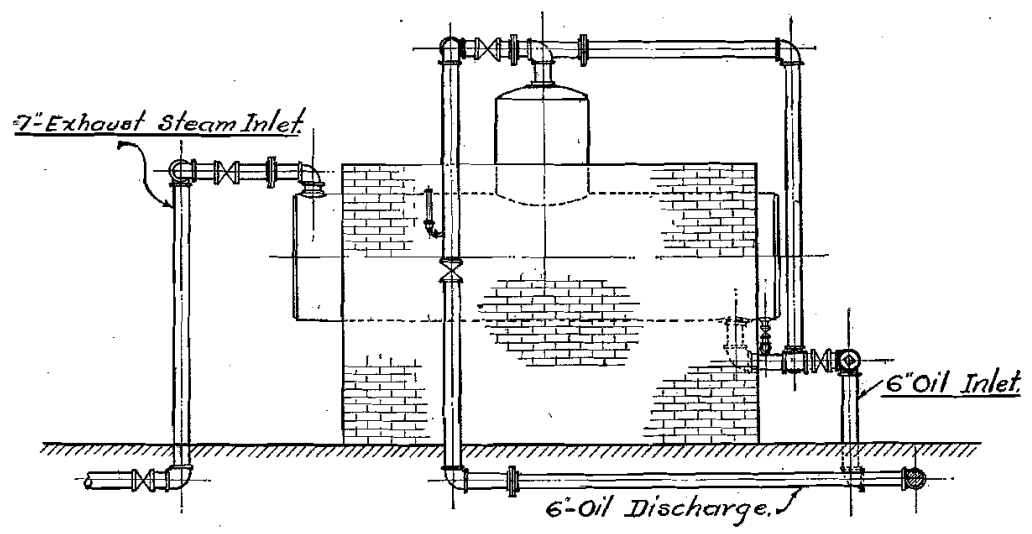

Fig. 2.-Firgt Oil-Heating Plant. Stde Elievation.

iron were made to connect the inlet and the outlet steam. Exhaust steam from the compressor and pumps of the central plant was carried 
through $75 / 8$-in. casing pipe, connected to the header and thus through the boiler tubes. The outlet was high enough for the condensed steam to gravitate back to the hot-water well of the central plant.

The plant was placed near the shipping tanks and close to the main line carrying oil from the wells to the shipping tanks.

The piping was arranged so that the oil could be run from the main through one, two, or all three boilers, usually traveling through all three; or the oil could be run direct through the line as before, in case of leakage in the plant. As no fire was used around this plant, there was no danger from that source.

This plant heated the oil to an average temperature of $170^{\circ} \mathrm{F}$. very satisfactorily, and with practically no attention or cost, outside of installation. The loss of about $10^{\circ}$ in transit to the tanks made about $60^{\circ}$ to be supplied by the live-steam coils in the tanks. The water-heating

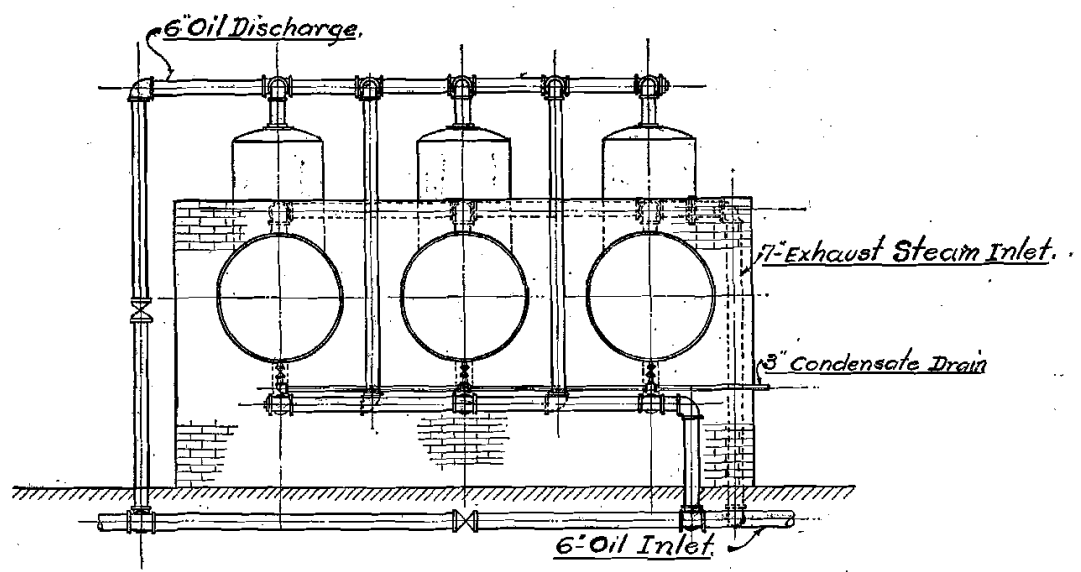

Fig. 3.-First Oil-Heating Plant. End Eumvation.

system was not adapted to the conditions and was discarded, the heat then being applied directly to the oil through the coils, but this was also too slow for the necessary operating capacity.

It is certain that the failure of this plant was due to insufficient heating of the oil, and a second plant was built with a view to correcting this difficulty. This plant was constructed as follows:

Two old 40-h.p. boilers were erected, with the typical oil-field mud setting, the boilers being suspended on pipe supports, with regular oil burners for supplying heat direct under boilers.

The piping was arranged so that oil could be run through either or both boilers, the oil being run in at the bottom and rear, and out at the dome; and again in at the bottom of the second boiler, through it and out to the storage reservoir, from whence it was pumped to the shipping 


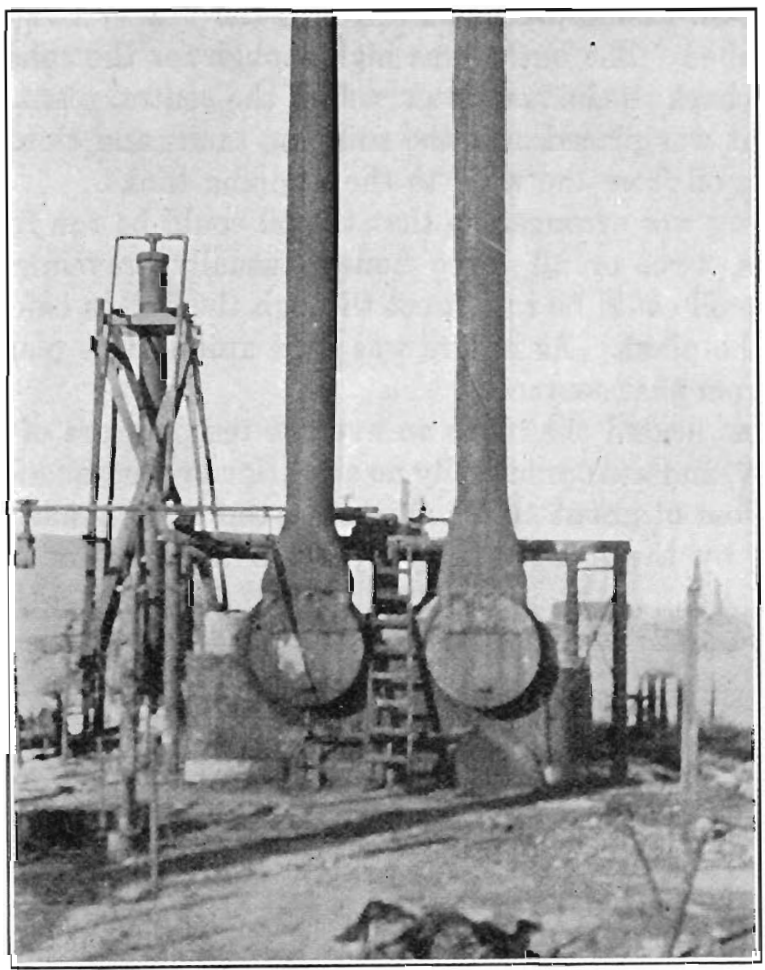

Fig. 4.-Second Oil-Heating Plant.

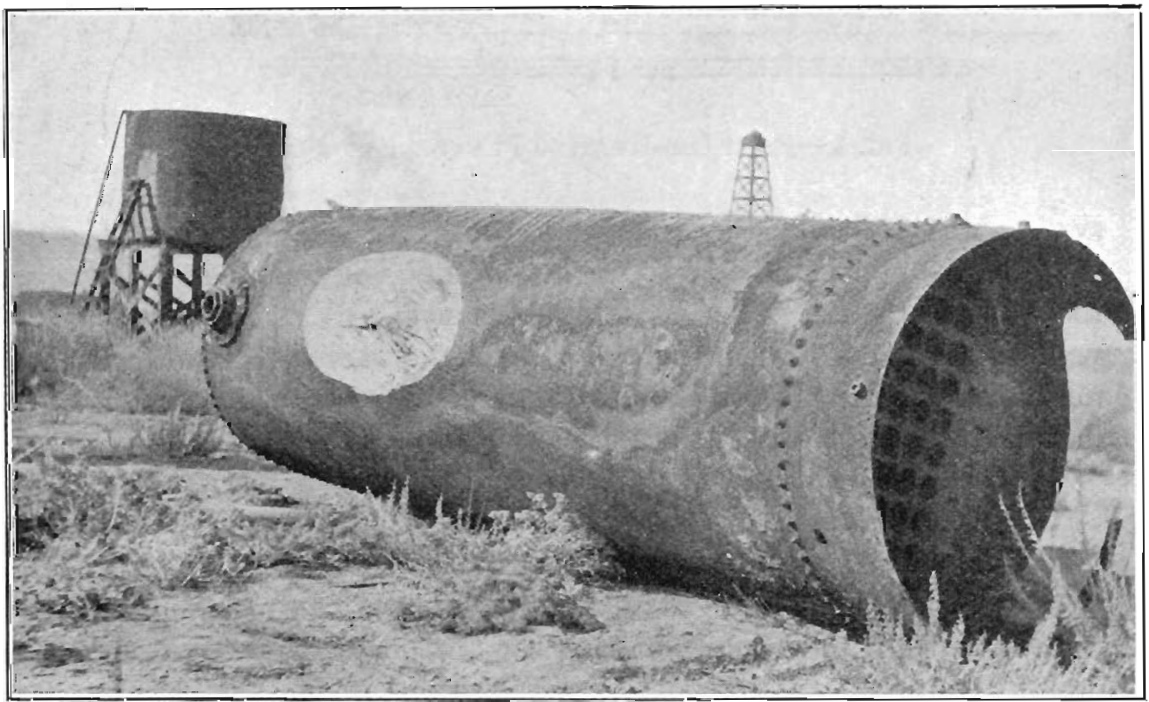

Fig. 5.-Burnt-Out Boiler, Showing Bagging. 
tanks. The heater was still used for this plant, and when both boilers were being used a light fire was carried under the first boiler, the heavier fire being applied to the second boiler. The 6-in. overflow delivery

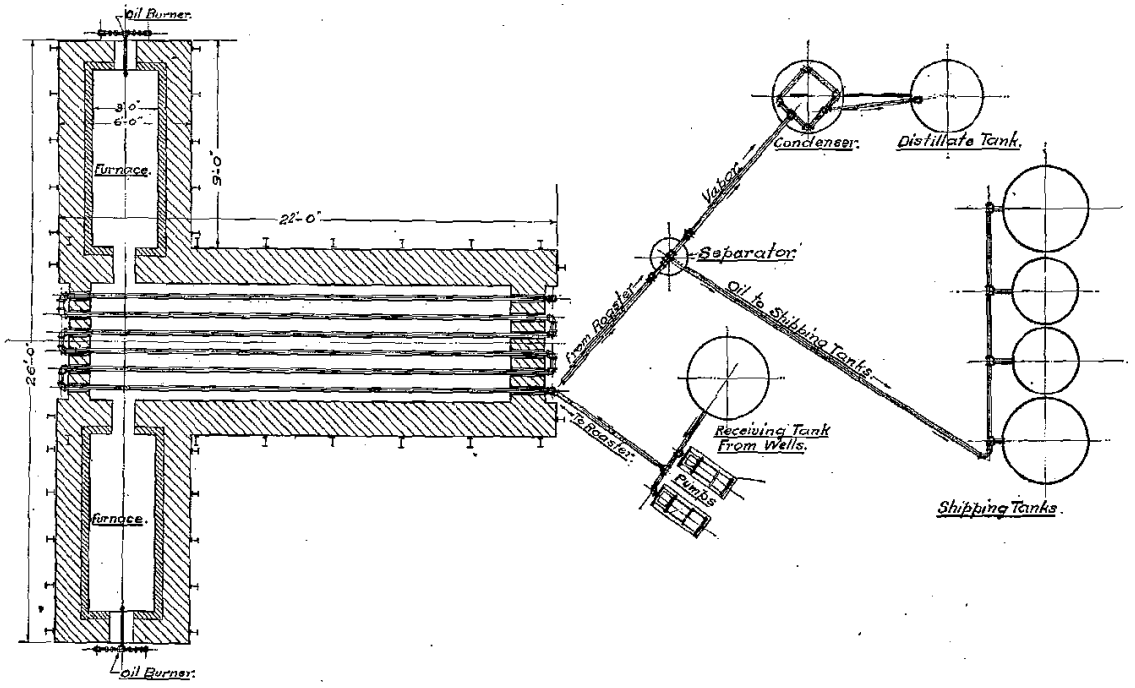

Fig. 6.-Oil-Dehydrating Plant of Nevada Petroleum Co., Coalinga, Car. Plan.

pipe was set on a slight up grade to the receiving tank at the reservoir to insure a back pressure on the boiler.

The gauges usually showed a pressure of a few pounds and a tem-

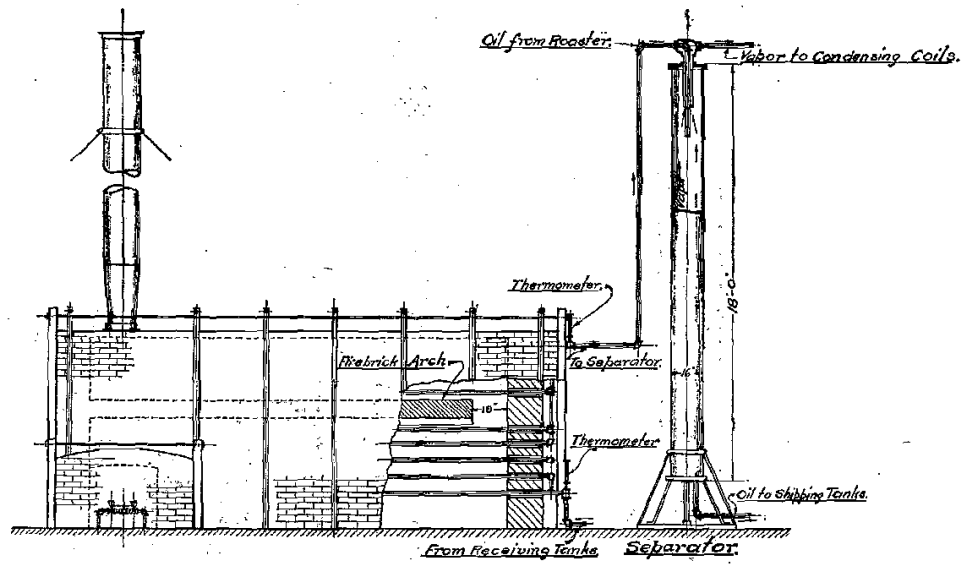

Frg. 7.-Oil-Dehydrating Prant. Side Elegvation.

perature from $230^{\circ}$ to $250^{\circ}$, it being necessary to carry it above the boiling point.

All piping was 6-in., with no constricted turns or openings in the system. No attempt was made to recover any light products. 


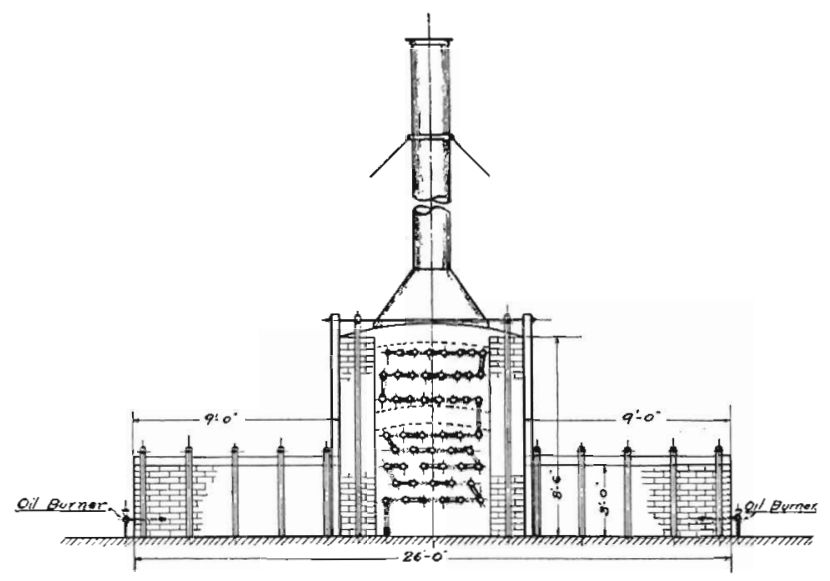

Fig. 8.-Oll-Dehydrating Plant. End Elevation.

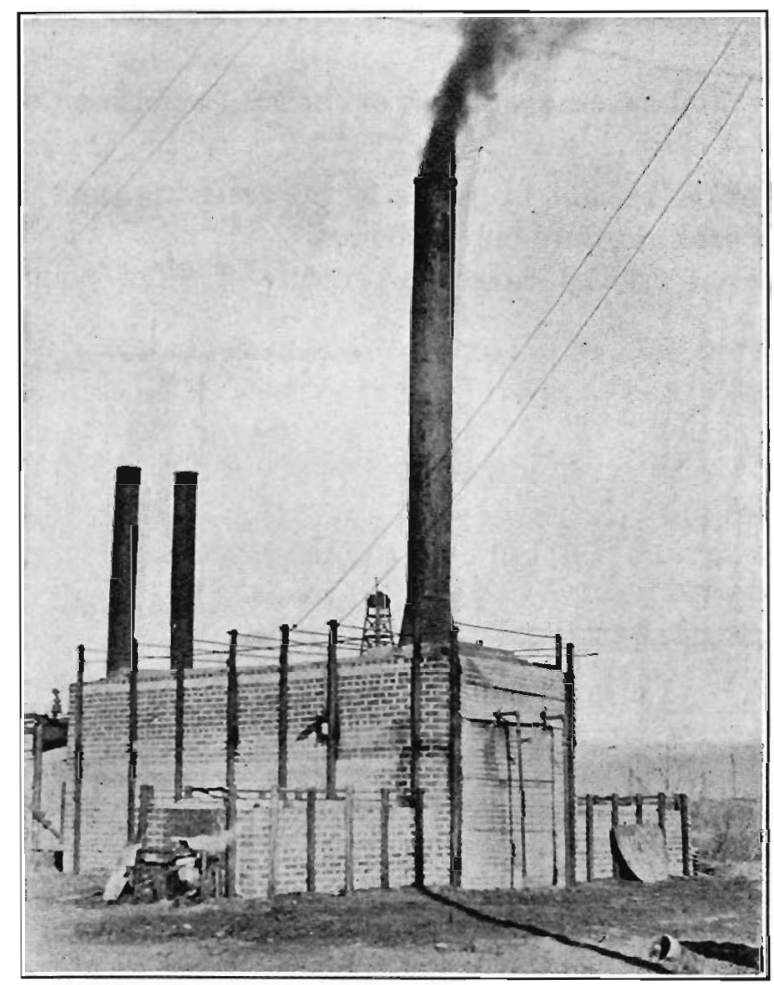

Fig. 9.-Oil-Degydrating Plantin Operation. 
While this plant did clean the oil, it was not a commercial success because of the excessive repairs, the sediment from the emulsion settling in the bottom of the first boiler causing blistering within a few days. These blisters had eventually to be cut out and patched and were the cause of several nasty fires owing to the boiler bagging and cracking and the oil running into the fire box. A burned-out boiler is shown in Fig. 5 .

The experiment had now reached such a stage that certain definite conclusions were possible, viz:

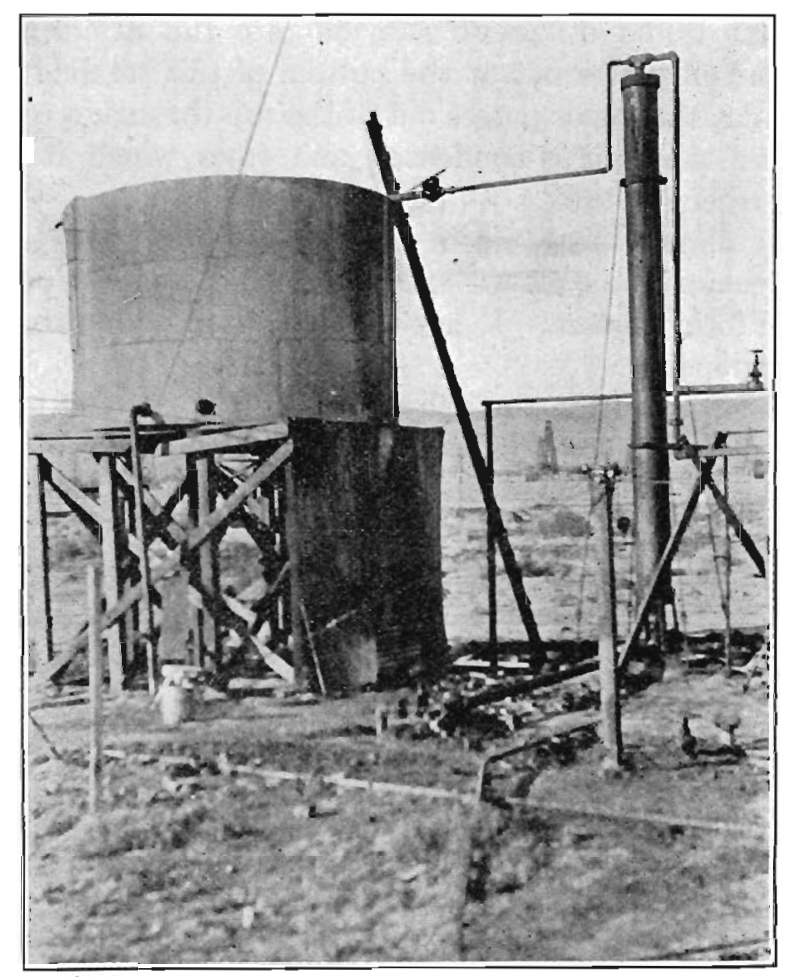

Fig. 10.-Separator and Condensing Apparatus.

1. Exhaust-steam coils cannot be used successfully for heating the oil because the temperature is not raised sufficiently high.

2. If a separation of the oil and water is to take place, the temperature must be raised to a point that will generate steam and cause an explosion in the oil-enveloped globules of water, thereby liberating the water and permitting it to separate from the oil.

The third plant was then built, consisting of brick walls lined with fre brick inside of which were coils of 3-in. pipe through which the oil was pumped. These coils were constructed in horizontal rows of five 
and six 20-ft. joints below the arch and eight joints in each of the three rows above, 52 joints in all.

Furnaces were built on either side of the front so that the flames would not come in direct contact with the coil. The heat from the furnace passes into the lower compartment, thence to the back and under the arch, then through the opening at the back, into the top compartment and out through the stack at the front end.

A receiver was erected for the oil as it left the roaster, the function of which is to separate the vapor from the oil and to recover the light products that would otherwise pass off into the atmosphere and be wasted. The oil passes out at the bottom of this receiver and into the shipping tanks, the vapor passes out of the top through a coil submerged in cold water, where it is condensed and from which it is allowed to collect in a receiving tank.

This last plant, illustrated in Figs. 6 to 10, has proved a complete success. Because the coils are small, the solids from the oil cannot precipitate and form blisters. It has been operated daily for the past year without any repairs.

The cost of operating the dehydrating plant per $100 \mathrm{bbl}$. treated is as follows: Labor, 75c.; fuel consumed, 74c.; steam consumed, 22c.; total, \$1.71. The condensation per 100 bbl. is: Water, 10.40; light oil, 0.43 ; total, 10.83. The gravity of the light oil is 37.2. The oil before treating showed: Temperature, $80^{\circ} \mathrm{F}$; specific gravity, 14.8; B. S. and M., 11.6 per cent. The oil after treatment analyzed: Temperature, $260^{\circ} \mathrm{F}$., specific gravity, 15.5 ; B. S. and M., 1.0 per cent. 